\title{
CONSTRUÇÃO DE CONHECIMENTOS POR MEIO DE REPRESENTAÇÕES FOTOGRÁFICAS: ASPECTOS SEMIÓTICOS E MATEMÁTICOS DA FOTOGRAFIA
}

\section{CONSTRUCTION OF KNOWLEDGE THROUGH PHOTOGRAPHIC REPRESENTATIONS: SEMIOTIC AND MATHEMATICAL ASPECTS OF PHOTOGRAPHY}

\author{
BACHMANN, Evelize Hofelmann ${ }^{1}$ \\ KURSANCEW, Thaisa Karina Kruger ${ }^{2}$ \\ PEREIRA, Kariston ${ }^{3}$ \\ PAVANATI, Iandra 4 \\ SELL, Fabíola Sucupira Ferreira ${ }^{5}$
}

\begin{abstract}
RESUMO
Este estudo tem como objetivo investigar, a partir das concepções semióticas de Charles Sanders Peirce (1839-1914) e Lúcia Santaella (1944- ) a construção de conhecimentos matemáticos por meio de representações semióticas da fotografia. Em sua obra, Peirce dedicou-se ao estudo de diversas áreas da ciência, sendo uma delas a da semiótica, que para o filósofo deve ser pensada como uma lógica, a qual será retratada neste trabalho. Nesse viés, a fotografia por meio da linguagem semiótica produz significado e sentido naquele que a observa, sendo pensada neste estudo como uma possibilidade de ferramenta para a aprendizagem matemática. Assim, por meio de uma pesquisa bibliográfica buscou-se a resposta para a seguinte questão: como construir conhecimentos matemáticos a partir de representações apresentadas pela fotografia? Como considerações finais, concluiu-se com a pesquisa que é possível promover a aprendizagem matemática por meio da fotografia com fotos do cotidiano, uma vez que, é possível encontrar elementos matemáticos no meio social,
\end{abstract}

\footnotetext{
${ }^{1}$ Mestranda em Ensino de Ciências, Matemática e Tecnologias (PPGECMT)- UDESC, Pós-Graduada em Tecnologias Educacionais - UNISOCIESC, Graduada em Design- Programação Visual UNIVILLE, Professora da Unisociesc e do SENAC (SC). e-mail: evelize.h@gmail.com

${ }^{2}$ Mestranda em Ensino de Ciências, Matemática e Tecnologias (PPGECMT)- UDESC, Graduada em Pedagogia - UDESC, Professora da Rede municipal de Joinville. e-mail: thaisakarina@gmail.com

${ }^{3}$ Doutor em Engenharia e Gestão do Conhecimento - UFSC, Mestre em Ciência da Computação UFSC, Bacharel em Ciência da Computação - UDESC, Docente Permanente do Programa de PósGraduação em Ensino de Ciências, Matemática e Tecnologias (PPGECMT). e-mail: kariston.pereira@udesc.br

${ }^{4}$ Doutora em Engenharia e Gestão do Conhecimento - UFSC, Mestra em Educação - UFSC, Graduada em História - UDESC, Professora do Grupo Educacional Censupeg e do Instituto de Ensino Superior Santo Antônio - INESA. e-mail: iandrapavanati@hotmail.com)

${ }^{5}$ Doutora e mestre em Linguística - UFSC, Licenciada em letras-Alemão e Bacharel em Letras-Libras - UFSC, Docente Permanente do Programa de Pós-Graduação em Ensino de Ciências, Matemática e Tecnologias (PPGECMT). e-mail: fabiola.sell@udesc.br
} 
bem como, a fotografia também possibilita a reflexão do contexto urbano sobre várias perspectivas.

Palavras-chave: Semiótica; Peirce; Fotografia; Matemática; Representações

\section{ABSTRACT}

This study aims to investigate, from the semiotic conceptions of Charles Sanders Peirce (18391914) and Lúcia Santaella (1944-), the construction of mathematical knowledge through semiotic representations of photography. In his work, Peirce devoted himself to the study of several areas of science, one of which is that of semiotics, which for the philosopher must be thought of as a logic, which will be portrayed in this work. In this bias, photography through semiotic language produces meaning and guidance in the one who observes it, being considered in this study as a possibility of a tool for mathematical learning. Thus, through a bibliographical research the answer was sought to the following question: how to build mathematical knowledge from representations presented by photography? As final considerations, it was concluded with the research that it is possible to promote mathematical learning by means of the photograph with daily photos, since it is possible to find mathematical elements in the social environment, as well as photography also allows the reflection of the urban context on various perspectives.

KeYwORDS: Semiotics; Peirce; Photography; Mathematics; Representations

\section{INTRODUÇÃo}

Compreender a matemática, muitas vezes, não é uma tarefa fácil. Muitos são os recursos hoje utilizados por professores a fim de fazer com que a aprendizagem da matemática se torne ainda mais significativa.

Considerando essa multiplicidade de recursos passíveis de contribuir com o ensino de matemática, emerge a reflexão acerca de por que não possibilitar que as imagens possam contribuir com a construção do conhecimento matemático? Nesse contexto, nada melhor que envolver a fotografia e todo o seu campo de significação. Para Nagamini (2016), as imagens podem se apresentar como um convite ao conhecimento. Pode-se assim afirmar que a fotografia pode ser considerada uma ferramenta de estudos, apresentando também aspectos históricos e culturais de uma sociedade.

Dado o contexto da sociedade pós-industrial, em que as tecnologias digitais são componentes cotidianos da vida de alunos e professores, Pavanati (2013) salienta o potencial didático-pedagógico do uso dessas ferramentas, as quais podem propiciar a interação professor/estudante em sala de aula. A produção e utilização pedagógica de imagens se caracteriza como propiciadora das aprendizagens dos estudantes, porque parte da imaginação se desenvolve de maneira interativa, destacadamente, no campo de domínio do professor. 
Por apresentarem tantas informações, deve-se levar em conta que aspectos semióticos são evidenciados, quando analisadas diferentes imagens. A semiótica, por sua vez, apresenta um estudo relacionado à ciência dos signos, sendo um campo útil e necessário quando o assunto é representação imagética.

Santaella (2008) enfatiza que nem mesmo o raciocínio matemático dispensa qualquer outra espécie de signo e que é necessário compreender as condições gerais do signo. Em relação a sua semioticidade, a matemática está diretamente associada à produção e ao uso de signos, em que constructos da semiótica peirceana podem possibilitar análises de fenômenos referentes ao ensino e aprendizagem da matemática (ALMEIDA; SILVA, 2018).

Partindo do pressuposto de que a aprendizagem ocorre por meio da linguagem, são os signos que viabilizam a linguagem. Neste sentido, Almeida e Silva (2018, p. 703) destacam que o ensino e aprendizagem da matemática também estão associados à produção e ao uso de signos, salientando que "podemos conjecturar que os constructos da semiótica peirceana podem servir para a análise de fenômenos no âmbito do ensino e da aprendizagem da Matemática".

Compreendendo a necessidade de identificar os signos nas mais diversas composições fotográficas é que propomos estruturar um estudo, apoiado nos conceitos e características da semiótica, com o intuito de investigar a partir das concepções semióticas de Charles Sanders Peirce (1839 - 1914) a construção de conhecimentos matemáticos por meio de representações semióticas da fotografia. Além deste objetivo, torna-se clara a intenção de observar os aspectos semióticos e matemáticos por meio da fotografia, pois se entende que a foto tem condições de dar suporte a diversos campos do conhecimento, sendo um deles, aspectos e conceitos matemáticos.

Por meio de uma investigação bibliográfica, o estudo aqui descrito apresenta um levantamento dos conceitos semióticos na visão de Peirce, considerando sua importância como filósofo e estudioso dessa ciência.

Por fim, apresentamos alguns exemplos bem-sucedidos do uso dos registros fotográficos como instrumentos alternativos para o compartilhamento do conhecimento e identificação de aspectos matemáticos. Estes levantamentos bibliográficos são uma conversa entre a fotografia, seus aspectos semióticos e as possibilidades da matemática nesta estrutura de informações.

\section{SEMIÓtICA E OS ESTUdOS DE PEIRCE}

Os estudos de Peirce, segundo Santaella (2008), são vastos e complexos, uma vez que o filósofo americano se dedicou a diferentes áreas da ciência, tais como: matemática, física, astronomia, química, linguística, psicologia, história, lógica e filosofia, buscando o conhecimento lógico dos métodos e fundamentos destas ciências. Desse modo, Peirce pensa a semiótica como uma lógica em um sentido muito amplo, 
uma vez que possibilita agir com base na razão, por meio do autocontrole crítico que o pensamento lógico auxilia a desenvolver. Diante disso, a autora explica a concepção peirceana da lógica para uma semiótica geral:

A lógica é a ciência das leis necessárias do pensamento e das condições para se atingir a verdade. Muito cedo, Peirce deu-se conta de que não há pensamento que possa se desenvolver apenas através de símbolos. Nem mesmo o raciocínio puramente matemático pode dispensar outras espécies de signos. Vem dessa descoberta a concepção peirceana da lógica para uma semiótica geral. Por isso, a lógica, também chamada de semiótica, trata não apenas das leis do pensamento e das condições da verdade, mas, para tratar das leis do pensamento e da sua evolução, deve debruçar-se, antes, sobre as condições gerais dos signos (SANTAELLA, 2008, p. 03).

Nesse sentido, o signo na definição de Peirce, segundo Santaella (2008), tem uma natureza triádica, podendo ser analisado no seu poder para significar, na sua referência àquilo que representa e nos tipos de interpretação que ele pode despertar. Logo, o estudo da semiótica possibilita o acesso interno das mensagens, na forma como são constituídas e nos métodos e recursos nelas utilizados. Além disso, a teoria de Peirce destaca que há três elementos formais e universais nos fenômenos que aparecem à percepção e à mente: primeiridade, que está relacionado ao acaso; secundidade que está associado às ideias de dependência; e terceiridade, que se refere à generalidade. Santaella (2008) relata que, segundo Peirce, a forma mais simples da terceiridade é o signo, uma vez que, este é o primeiro que aparece à mente, associando um segundo, aquilo que o signo representa, a um terceiro, impacto que 0 signo irá ocasionar para um possível intérprete. A autora define o signo da seguinte forma:

O signo é qualquer coisa de qualquer espécie (uma palavra, um livro, uma biblioteca, um grito, uma pintura, um museu, uma pessoa, uma mancha de tinta, um vídeo etc.) que representa uma outra coisa, chamada de objeto do signo e que produz um efeito interpretativo em uma mente real ou potencial, efeito este que é chamado de interpretante do signo (SANTAELLA, 2008, p. 08).

Portanto, a compreensão da lógica triádica do signo é fundamental para entender que a definição peirceana do signo engloba três teorias: a da significação, a da objetividade e a da interpretação. Além disso, o filósofo destaca três propriedades formais que as coisas têm e que lhes dão possibilidade para atuar como signo: sua qualidade, sua existência e seu caráter de lei. Nesse sentido a qualidade pode funcionar como signo como, por exemplo, ao analisar a cor azul-celeste, a cor por si só não é o céu, mas parece e propõe isso. $O$ fato de existir faz do que existe um signo, 
uma vez que, o existente ocupa um lugar dentro de um contexto, tempo e espaço, bem como, relaciona-se a outros existentes para inúmeras direções, as quais são suas referências possíveis. Assim, o existente se torna um signo das referências que aponta. Quando alguma coisa tem propriedade da lei faz com que o singular se molde à sua generalidade e, desse modo, o caráter de lei capacita algo para funcionar como um signo.

Diante disso, dependendo da propriedade do signo considerada, a forma como este pode representar seu objeto também será diferente. São três tipos de relação que o signo pode ter com o objeto utilizado. Quando a qualidade for à propriedade considerada, o signo será um ícone, quando for um existente, será um índice e quando for uma lei, será um símbolo.

Peirce separou os signos icônicos, os quais atuam como signo devido à relação de semelhança com seus objetos, em três categorias: imagem, diagrama e metáfora. A imagem constitui uma relação de semelhança com seu objeto no nível de aparência, e pode representar objetos quando retrata similaridades com a forma como estes são percebidos visualmente. Nesse sentido, a semiótica da fotografia está baseada na semiótica da imagem. É fundamental, portanto, o estudo desta para a compreensão das representações semióticas da fotografia.

\section{SEMIÓTICA DA FOTOGRAFIA}

De acordo com Santaella e Nöth (2005, p.107), "a semiótica da fotografia se baseia na semiótica da imagem". Mas por que relacionamos a fotografia à semiótica? É possível identificar a semiótica na fotografia, pois a foto pode funcionar, ao mesmo tempo, como ícone e índice. Ambos os elementos estão ligados à semiótica.

Segundo Flores (2002), a iconicidade se faz presente e é considerada o princípio que estabelece uma relação não-arbitrária entre a função e a forma, ou mesmo entre o código e a mensagem relacionada à linguagem humana.

Peirce apresenta diversos aspectos referentes à qualidade sígnica da fotografia. Um deles refere-se à definição do signo em relação ao objeto. As fotos são consideradas icônicas, ou seja, "são exatamente como os objetos que representam" (SANTAELLA; NÖTH, 2005, p.107).

Santaella e Nöth (2005) relatam questões significativas de Barthes (1961) em relação ao paradoxo fotográfico. Por meio do paradoxo de Barthes (1961), as fotos apresentam como importante característica a "perfeita analogia" relacionada à realidade que transmite. Ao mesmo tempo que a fotografia apresenta a realidade, ela também a cria, o que pode, muitas vezes, distorcer a imagem representada.

Em sua etimologia, a palavra "fotografia", incorpora phos-luz e grafos-escrita. Ou seja, escrita com luz. 


\section{O SIGNO FOTOGRÁFICO PARA PEIRCE}

Ao compreender que a semiótica estuda os signos e que os signos possuem uma natureza triádica em seu significado, torna-se importante identificar a visão de Peirce em relação à natureza e à significância da fotografia. O filósofo destacou que há diversos aspectos relacionados à qualidade sígnica da fotografia.

É assim que as fotos são, de certo modo, exatamente como os objetos que elas representam e, portanto, icônicas. Por outro lado, elas mantêm uma ligação física com seu objeto, o que as torna indexicais, pois a imagem fotográfica é obrigada fisicamente a corresponder ponto por ponto à natureza (SANTAELLA; NÖTH, 2005, p.110).

Além da qualidade sígnica, Peirce relata o fator relacionado à reprodução técnica da fotografia. A primeiridade, segundo Peirce, está ligada ao negativo de uma foto, considerado um legisigno ${ }^{6}$. Isto porque um único negativo pode ser reproduzido inúmeras vezes. Sendo assim, cada cópia acaba se caracterizando, por sua unicidade, como um sinsigno 7 .

Mas, será que as questões pensadas para a imagem analógica assumem valores semelhantes às imagens digitais? Assim como a fotografia tradicional difere da pintura, pode-se entender que a imagem digital se difere da fotografia tradicional em relação à realidade física. Da mesma forma que a fotografia tradicional está ligada a processos analógicos, a imagem digital está codificada e subdividida em pixels. "Na fotografia tradicional, o suporte é o negativo. Na imagem digital, a resolução tonal é limitada e contém uma quantidade fixa de informações" (SOUSA, 1999, p. 77).

Mesmo havendo diferenças entre a fotografia digital e a analógica, a foto continua sendo uma testemunha de um acontecimento, posto que, tal como exemplificam Santaella e Nöth (2005, p. 198), "fotos de família nos lembram situações reais vividas no passado, fotos jornalísticas que documentam um evento histórico, ou as fotos científicas, que mostram um objeto real do mundo em todos os seus detalhes".

Com isso não se espera, por outro lado, negar que a correspondência fotográfica possa ser manipulada. Os autores Santaella e Nöth (2005, p. 198) deixam bem esclarecido que:

Através de retoque, o significante referente a um objeto existente pode desaparecer. Pela montagem, um objeto não existente pode fazer parte da cena. Assim, a fotografia tornou-se um meio que se prestou à manipulação, logro, simulações e falsificações. Os mais recentes

\footnotetext{
${ }^{6}$ O legisigno, segundo Santaella (1983, p. 67) é portador de uma lei, convenção ou pacto.

${ }^{7}$ O sinsigno, segundo Niemeyer (2003, p.35) é o aspecto do signo que já particulariza e individualiza como ocorrência; é sua forma, suas dimensões.
} 
desenvolvimentos na computação gráfica, com as novas possibilidades de combinações de formas, distorção, simulação e outros modos de manipulação de imagem digital, aumentaram bastante este potencial de ilusão do meio.

Considerando a terceiridade em relação à fotografia, Peirce estabelece que a imagem fotográfica faz uma afirmação sobre o objeto representado. A impressão fotográfica em si não transmite nenhuma informação, mas se pensarmos que a fotografia é a captura instantânea de uma secção de raios, ela se faz um Dici-signo, pois já não temos dúvidas de que seja uma fotografia, embora ainda não tenhamos estabelecido um argumento ou significado final para ela. A relação estabelecida entre a impressão da fotografia, considerada o quase-predicado da fotografia, juntamente com a secção dos raios, sendo quase-sujeito, forma a sintaxe do Dici-signo. O Dicisigno está ligado à terceira tricotomia referente à semiótica (SANTAELLA; NÖTH, 2005). Nesse sentido, Santaella e Nöth (2005, p. 150) ainda explicam que: "imagens se tornam símbolos quando o significado de seus elementos só pode ser entendido com a ajuda do código de uma convenção cultural. Veículo do signo (primeiridade) e objeto (secundidade) tem que ser associados através de um terceiro, a convenção cultural, ainda a ser aprendida, por um intérprete (o terceiro)".

Pode-se entender a partir de Machado (2001 p. 19), que do desenvolvimento das tecnologias digitais, decorre a passagem da cultura da reprodutibilidade para 0 "alvorecer da cultura do virtual". Isto se dá porque nos sistemas de reprodução analógica sempre há a perda de informação, maior a cada geração de cópias. Porém, deixando de ocorrer a partir do tratamento digital da informação, porque nenhum pixel é aumentado ou subtraído de uma cópia digital. Com isso, para o autor, "as mensagens que circulam nos modernos canais eletrônicos e informáticos pertencem à ordem da distribuição e não mais da reprodução".

É importante observarmos que, com relação à proposição de uma estratégia sobre como tornar mais significativo o processo de ensino e aprendizagem por meio de imagens fotográficas, surge na sociedade, a partir da introdução das tecnologias digitais, "uma nova sensibilidade e uma nova percepção de tempo e espaço" (AZEVEDO; OLIVEIRA; LARDOSA, 2008, p. 1642). Assim, as tecnologias digitais, além de potencializar a capacidade pedagógica das imagens, contribuem para a emergência de uma nova forma de representar o imaginário humano, promovendo, portanto, também alterações nas formas de produzir e disseminar o conhecimento.

\section{Código FOTOGRÁFICO}

A imagem fotográfica pode ser identificada como uma mensagem multicodificada. Além de apresentar a verdadeira informação icônico-fotográfica, a foto tem a propriedade de transmitir mensagens que apresentam codificações biossociais, psicossociais, simbólicas, retóricas ou linguísticas (SANTAELLA; NÖTH, 2005). Isto nos 
leva a entender que a fotografia traz variadas informações e transmite as mais diferentes mensagens, dependendo da leitura dela realizada. Analisando as mais diferentes informações que uma fotografia pode apresentar, podemos compreender a riqueza de analogias, elementos e suas possibilidades.

Na fotografia há um processo de produção diádico, em que as técnicas óticas de formação da imagem provêm a partir de uma emanação luminosa sobre um suporte preparado para reagir ao receber o estímulo da luz. O resultado desta "colisão ótica" é o confronto entre um sujeito que olha e o real que é capturado. Esse sujeito estabelece um recorte do real que é extraído do fluxo do tempo e a imagem produzida, "é sempre um duplo, emanação direta e física do objeto", é um fragmento e um vestígio do real, mas, também, uma forma de apresentação de algo que não é mais presente (SANTAELLA; NÖTH, 2005, p. 165).

Já no paradigma pós-fotográfico, inaugurado a partir do surgimento dos equipamentos digitais, a produção de imagens é um processo triádico, onde a realidade não se impõe como elemento constitutivo, nem do objeto criado, nem da fonte de criação. Este novo paradigma rompe com as leis físicas da ótica, importantes para a consecução das imagens até o paradigma fotográfico, e inaugura a dominância da matemática na construção de imagens por meio da programação computacional. Conforme explica Santaella (2005),

Via digitalização, quaisquer fontes de informação podem ser homogeneizadas em cadeias sequenciais de 0 e 1 . Essas cadeias são chamadas bits. Um bit não tem cor, tamanho ou peso e é capaz de viajar à velocidade da luz. É o menor elemento atômico no DNA da informação. É um estado: ligado ou desligado (SANTAELLA, 2005, p. 389).

Tal revolução paradigmática na fotografia também interfere nos processos cognitivos dos sujeitos produtores e consumidores dessas imagens. Se relacionarmos a fotografia com o ensino de matemática, essa revolução pode significar uma renovação nas metodologias didáticas, garantindo uma atualização e contextualização das práticas pedagógicas do ensino da matemática.

\section{APRENDIZAGEM DA MATEMÁtICA E A REPRESENTAÇÃo SEMIÓTICA}

Alguns questionamentos podem ser feitos em relação à representação da semiótica e ao funcionamento cognitivo da compreensão em matemática. Tais questionamentos estão relacionados às dificuldades dos alunos em compreender a matemática, entender as dificuldades durante o processo, e saber onde estas dificuldades se encontram. Questões dessa natureza são relevantes, pois existe uma exigência maior no que diz respeito à formação em matemática inicial para todos os alunos. $O$ entendimento dessas questões possibilita o auxílio no preparo dos alunos 
para o enfrentamento de um ambiente informático e tecnológico cada vez mais complexo.

Para responder a tais questionamentos, não podemos nos ater apenas ao campo matemático ou à sua história. A abordagem cognitiva deve ser evidenciada, pois o objetivo do ensino da matemática não está atrelado apenas à formação matemática e nem à ação de formar futuros matemáticos. É uma questão de contribuição para um desenvolvimento mais completo em relação às capacidades de raciocínio e de visualização.

Nesse sentido, ao observar a história da matemática, é notável que o desenvolvimento das representações semióticas seja fundamental para a evolução do pensamento matemático. Isso fica evidente, ao observar, segundo Machado (2013), a enorme variedade de representações semióticas utilizadas em matemática como, por exemplo, os sistemas de numeração, as figuras geométricas, as escritas algébricas e formais, as representações gráficas e a língua natural.

Dessa forma, a fotografia pode ser uma ferramenta para a aprendizagem matemática, pois é possível extrair dela elementos pertencentes à matemática como, por exemplo, figuras geométricas, percepção, espaço, enquadramento, tipos de planos, composição, dentre outros.

Diante disso, ao observar a realidade, os seres humanos desde o seu nascimento estão imersos em um universo no qual os conhecimentos matemáticos se fazem presentes em inúmeras situações do dia-a-dia, seja numa simples ida ao mercado ao contar o dinheiro, como no trânsito ao calcular e observar as placas de trânsito, ao observar as formas de um prédio, bem como, ao elaborar hipóteses para resolver um problema. Sendo assim, considerando a matemática sob o enfoque fotográfico, é possível evidenciar a sua presença e importância na vida dos seres humanos, compreendendo a realidade sob um recorte, um olhar para os elementos reais, existentes em um plano aparente.

\section{ANÁLISE FOTOGRÁFICA E A MATEMÁTICA}

Já sabemos que a fotografia tem o poder de apresentar diversas informações e analogias e, como um signo, a fotografia tem a possibilidade de representar elementos de acordo com sua apresentação. Por meio destas informações, torna-se possível analisar as mais diversas formas de associar a matemática às imagens constituídas por meio da fotografia.

Todos estamos inseridos em culturas. Fazemos parte de uma determinada cultura dominante e nosso olhar, geralmente está contextualmente inserido, ocorrendo assim processos condicionados de construção visual. Entretanto, nem sempre observamos o mundo que nos cerca. Observamos imagens, fotografias e muitas vezes não entendemos sua narrativa. A fotografia está presente em todos os lugares. Mesmo assim, muitos observam e não compreendem sua narrativa. Isso nos faz refletir que 
as imagens são codificadas, e que há necessidade de entendermos a mensagem que elas estão apresentando (BRUM; SCHIMIDT, 2014).

Além de fatores culturais, sociais, ou mesmo emocionais, a fotografia pode nos apresentar muito mais que um discurso. Por meio desta representação visual é possível abstrair outros elementos. Por meio de fotografias é possível encontrar elementos matemáticos no meio social. Para Brum e Schimidt (2014, p. 45), "a aprendizagem matemática não se limita ao racionalismo de números ditos exatos, mas também está relacionada com o nosso cotidiano e a nossa cultura".

Brum e Schimidt (2014) apresentam um projeto desenvolvido intitulado Fotografando a Matemática, em que os alunos de uma escola pública tiveram a oportunidade de aprender a matemática através de registros fotográficos. A ideia do projeto era de ensinar aos alunos a manusear as máquinas fotográficas e abstrair de seu cotidiano fotografias que apresentassem elementos matemáticos. Os autores afirmam que "a relação da Matemática com a fotografia mostrou-se um método eficaz para a construção do conhecimento e uma estratégia produtiva para discutir a cultura midiática com jovens da rede pública" (BRUM; SCHIMIDT, 2014, p. 42).

Por meio desse projeto, os alunos envolvidos tiveram a oportunidade de colocar em prática os conhecimentos adquiridos em sala de aula.

A figura 1 apresenta algumas fotografias dos alunos, com o intuito de identificar formas geométricas através de imagens de estruturas e objetos de seu cotidiano.

Fig. 1: Fotografias do Cotidiano
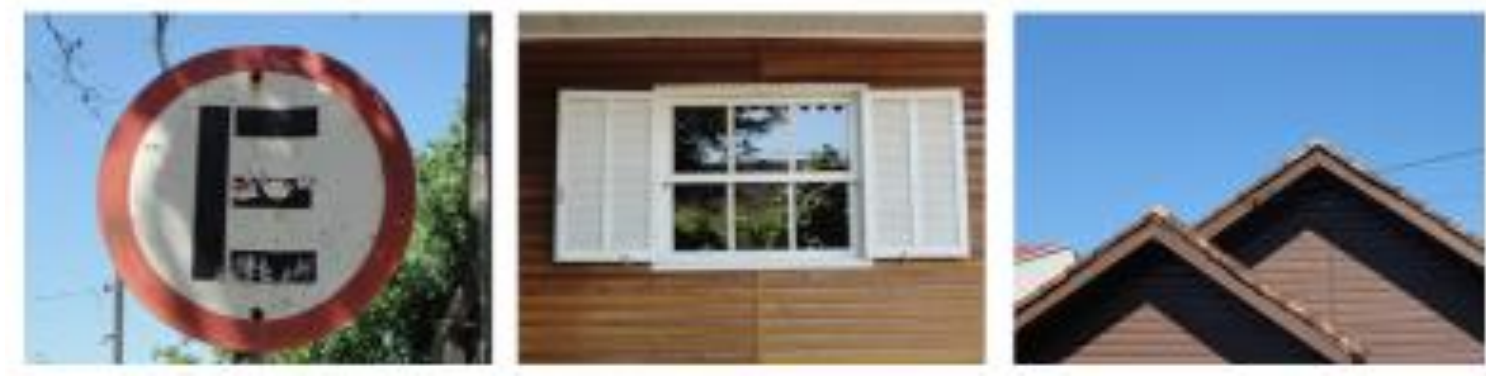

Fonte: Brum e Schimidt (2014)

Durante o projeto, além de fotografarem imagens do cotidiano, os alunos também traziam de casa objetos que remetessem às formas geométricas para que pudessem fotografar em um estúdio fotográfico (BRUM; SCHIMIDT, 2014).

Para Busatta (2014, p. 51),

Aliar a fotografia à Matemática é uma experiência que permite os alunos a serem mais ativos nas aulas. Serem mais responsáveis pela construção do seu conhecimento. A sala de aula passou a ser as ruas do Bairro, num ambiente amplo, livre, deixar o aluno explorar os conhecimentos, construir novos saberes através do olhar das lentes de uma máquina fotográfica, a Matemática num contexto vivo. 
Ainda em relação à contribuição da fotografia como objeto de reflexão, Ramos (2012) afirma que a fotografia possibilita a reflexão sobre o contexto urbano, por exemplo, sob várias perspectivas, sendo a principal os aspectos relacionados à matemática. A fotografia apresenta um signo de lei, possibilitando efeitos emocionais, reativos e até mesmo despertando diversos tipos de reflexões.

Morita (2017) apresenta, por meio da fotografia, imagens que contemplam formas e padrões geométricos de composições feitas em meio aos cenários urbanos da cidade de São Paulo.

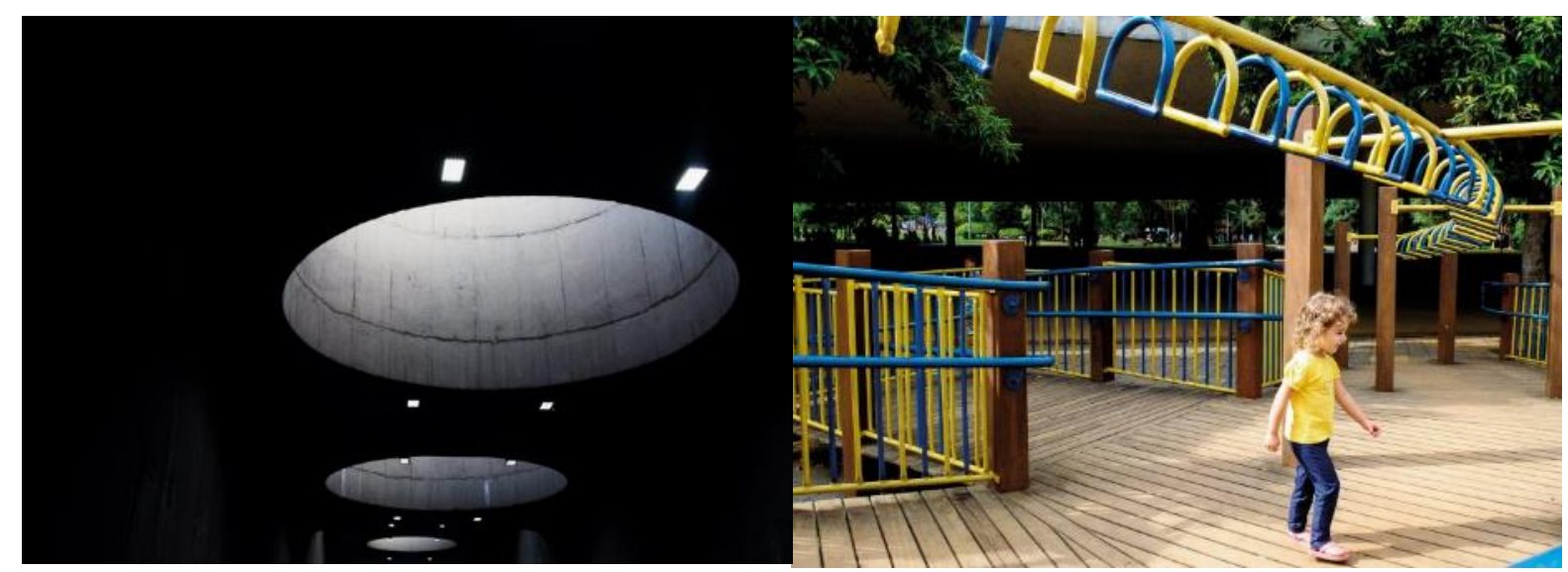

Fig. 2: Fotografias cenários urbanos de São Paulo Fonte: Morita (2017)

Por meio dessas fotografias, Morita $(2017$, p.1) relata sua percepção em relação às imagens fotográficas.

Neste ensaio, o olhar do fotógrafo busca enquadrar a geometria presente em cenas urbanas do cotidiano de um paulistano. Despertaram minha atenção para o clique um acontecimento, um lugar, uma sombra, as linhas, os ângulos que as formas apresentam. Os triângulos são as formas que mais costumo perseguir em imagens, ou acabam surgindo de forma natural por buscá-las em tudo que vejo. Desde os primórdios da pintura se tem conhecimento sobre o efeito de harmonia criado numa composição cujos elementos resultam em formas geométricas como o triângulo.

Essa percepção do autor confirma a importância e os diferentes significados que podemos encontrar nas imagens fotográficas. Não apenas um signo, não apenas 
representação, mas as fotografias vão além da imaginação, podem representar um momento, registrar um acontecimento, ensinar por meio de sua composição.

Portanto, é possível compreender, segundo Sousa (2005, p. 17), que a percepção se constitui "na relação entre os estímulos percebidos pelos sentidos e as respostas próprias do sujeito sensível", logo, alterando a percepção, altera-se também os modos de responder aos estímulos. Com isso pode-se inferir que os sujeitos contemporâneos, imersos num universo em que as imagens são reproduzidas e ressignificadas, têm diferentes possibilidades de interferirem e se apropriarem dessa realidade.

Ainda no contexto relacionado à fotografia e sua contribuição ao ensino de matemática, Santos e Nacarato (2014) apresentam experiências a partir de um projeto realizado com crianças do quinto ano do Ensino Fundamental de uma escola pública, a fim de inovar as práticas do ensino de matemática, mais especificamente, em relação ao ensino da geometria.

Utilizando uma máquina fotográfica, os alunos registraram imagens do espaço da escola e, por meio destes registros, exploraram conceitos matemáticos de espaço e forma. O projeto teve como ponto de partida os registros fotográficos relacionados ao espaço físico da escola, onde os alunos aplicaram seus conhecimentos e estudos sobre sólidos geométricos. O objetivo da atividade era fazer com que os alunos fotografassem os espaços da escola, com a intenção de encontrar elementos que possibilitassem estabelecer uma relação com a geometria.

Antes de os alunos iniciarem os registros fotográficos, os professores apresentavam as informações relacionadas à matemática, onde em sala de aula todos tinham acesso a conhecimentos prévios de geometria e, por consequência, saíram a campo a fim de encontrar formas geométricas de acordo com o que a professora apresentou em sala.

Os alunos saíram a campo com suas máquinas fotográficas e realizaram um percurso em torno da escola a fim de registrar objetos do cotidiano que remetessem a prismas, pirâmides e corpos redondos.

Um dos alunos relata seus registros, primeiramente explicando cada uma das fotos. A primeira fotografia é um pote e para a aluna 1 , parece um prisma. 0 segundo objeto é uma lixeira e para a aluna 1 este objeto se parece com um cilindro. A última fotografia é um mural. A aluna 1 acredita que este objeto se parece com um prisma. 
Fig. 3 Fotografias dos Alunos
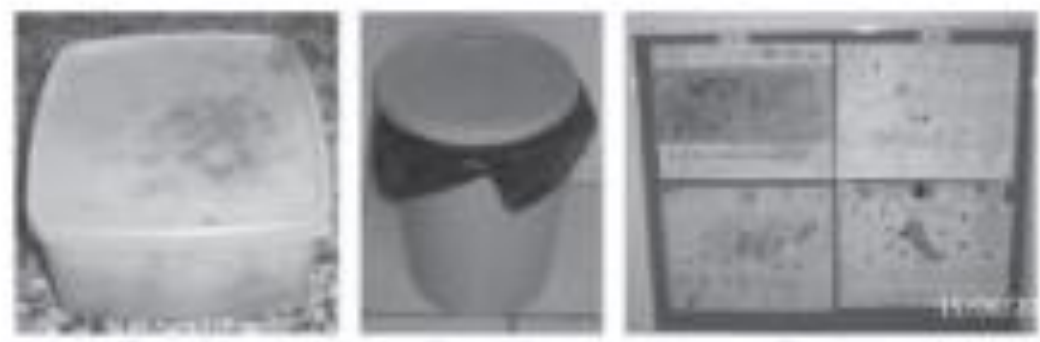

Fonte: Santos; Nacarato (2014, p. 57)

Santos e Nacarato (2014) afirmam, por meio dos resultados obtidos através do projeto construído junto aos alunos, que o uso da fotografia potencializou o ensino da geometria e possibilitou uma aula diferenciada da tradicional, conforme comentam:

Acreditamos que a fotografia tenha se tornado elemento sedutor em sala de aula: encantou e desestabilizou. Encantou pela possibilidade de os alunos saírem do espaço delimitado da sala de aula e compreenderem que há outros ambientes de aprendizagem na escola. Desestabilizou por romper um modelo tradicional de aula de matemática (SANTOS; NACARATO 2014, p.102).

Em relação às análises realizadas por meio das fotografias, Santos e Nacarato (2014) afirmam que as fotografias vão muito além das imagens, pois tais registros trazem a ideia de movimento, conceitos e subjetividade, já que os alunos se tornaram protagonistas no momento em que analisaram e registraram os objetos de acordo com a percepção de geometria aprendida em sala de aula. Por meio da fotografia, tornouse possível identificar e conceitualizar a presença da matemática em objetos fotografados na escola.

No estudo sobre o papel que exerce a imagem fotográfica em livros didáticos de matemática Maciel, Rêgo e Carlos (2017) analisaram de um modo geral, como as imagens fotográficas poderiam desenvolver conteúdos de matemática em livros didáticos dos quatro anos finais do Ensino Fundamental. Os autores investigaram o conteúdo relacionado à simetria com o intuito de compreender como a fotografia poderia explorar esse assunto nos livros didáticos de matemática. Os autores destacam que as imagens analisadas levaram em consideração algumas funções:

[...] as imagens fotográficas foram abordadas levando em conta as funções epistêmica, ilustrativa, comunicativa e decorativa. Enquanto a função epistêmica medeia, colabora, remete, apoia a construção de objetos matemáticos, a ilustrativa chama atenção para um determinado conteúdo matemático, a comunicativa estabelece uma comunicação entre a imagem e o leitor para através dessa transmitir alguma informação e a decorativa adorna, enfeita, embeleza, torna mais atraente a página do livro didático (MACIEL; RÊGO; CARLOS, 2017 p.357). 


\section{o estudo.}

Segue abaixo algumas imagens fotográficas destacadas pelos autores durante

Fig. 4: "A presença dos aspectos caracterizadores da contextualização matemática: na natureza, nas artes e na ciência".

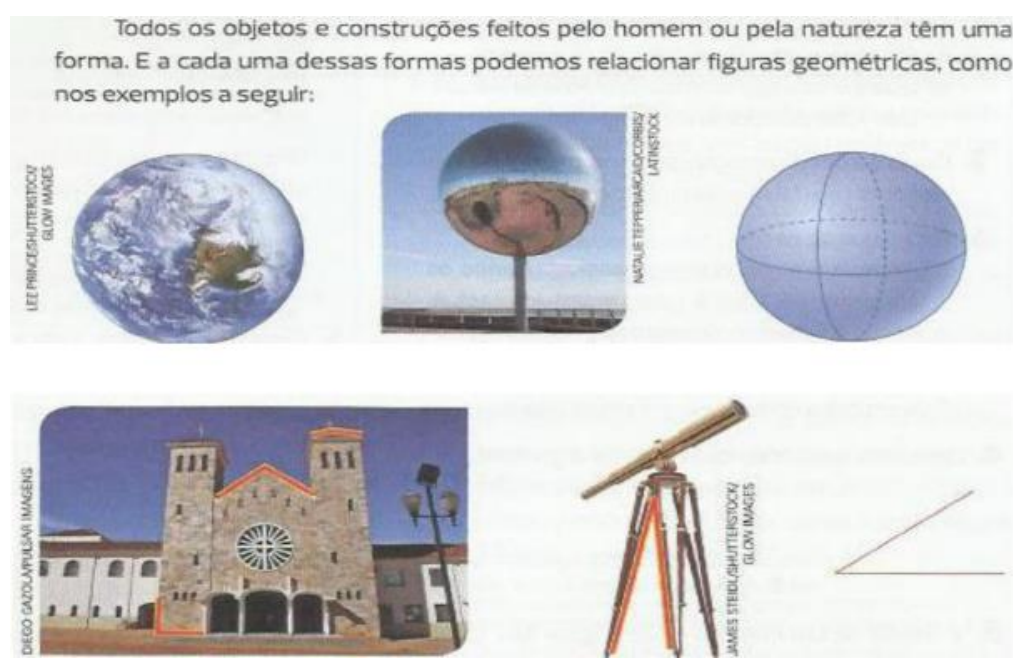

Fonte: Dante (2012, p. 66) apud Maciel; Rêgo; Carlos (2017, p. 356)

A figura quatro foi retirada do livro didático de matemática do $6^{\circ}$ ano; nela os autores Maciel, Rêgo e Carlos (2017, p. 356) identificam "a presença dos aspectos caracterizadores da contextualização matemática: na natureza, nas artes e na ciência". Com essas imagens o autor do livro didático pretendeu estudar as figuras geométricas, afirmando que aqueles objetos e construções evidenciados na figura podem ser relacionados às figuras geométricas.

Fig. 5: Registros numéricos dos povos da antiguidade
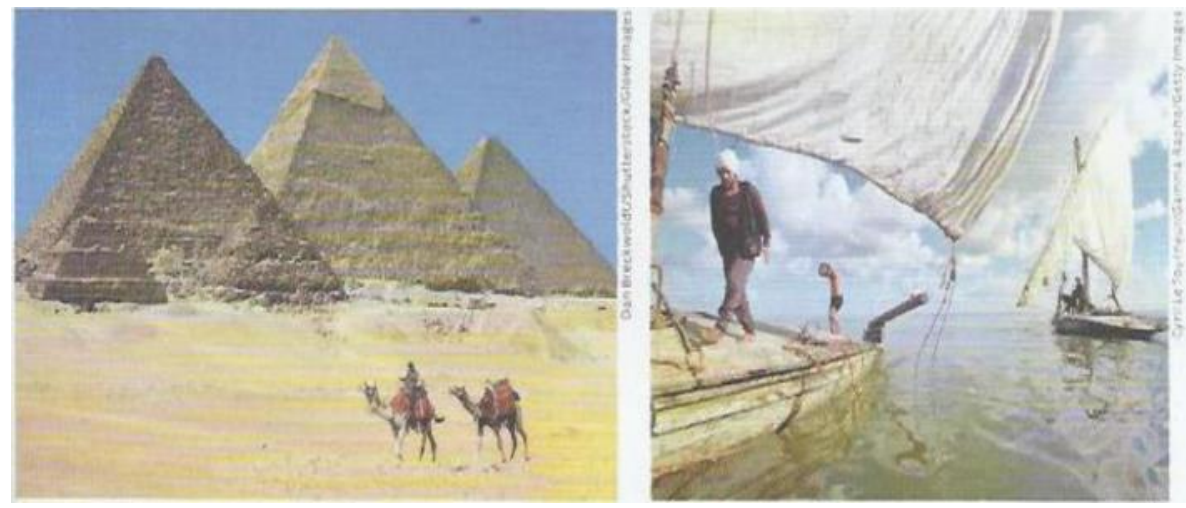

Fonte: Lopes (2012, p. 23) apud Maciel; Rêgo; Carlos (2017, p. 354). 
A figura cinco também foi retirada do livro didático do $6^{\circ}$ ano e está associada ao conteúdo sobre os registros numéricos dos povos da antiguidade, informando que os egípcios foram um dos primeiros povos a criar um sistema numérico. No entanto, Maciel, Rêgo e Carlos (2017) entenderam que as imagens fotográficas têm a intenção de ilustrar o assunto a ser estudado, porém não houve relação epistêmica entre conteúdo e imagem, uma vez que, a imagem teve a intenção de situar aspectos geográficos e culturais do Egito. Além disso, as imagens das pirâmides poderiam ser interpretadas de uma maneira diferente se estivessem relacionadas ao conteúdo matemático de pirâmides, segundo os autores do estudo.

Além de a fotografia oportunizar saberes em diferentes contextos, pode-se entender que as imagens fotográficas apresentam representações semióticas, sendo este um elemento fundamental para a evolução do pensamento matemático. (MACHADO, 2013). Para compreendermos e analisarmos uma imagem, é preciso entender que elas são compostas por signos. No caso das fotografias aqui apresentadas, a composição acontece por meio de signos não verbais. De acordo com Santaella (2006, p. 78), "o signo é uma coisa que representa uma outra coisa: seu objeto. Ele só pode funcionar como signo se carregar esse poder de representar, substituir uma outra coisa diferente dele". Nesse sentido, é possível compreender que os elementos encontrados nas fotografias se caracterizam por representar algo e, no caso dos exemplos aqui apresentados, os signos podem representar elementos da matemática.

\section{CONSIDERAÇÕES FINAIS}

Ao observamos as imagens fotográficas, identificamos as mais variadas informações e intenções que a imagem tem a apresentar. Por meio da leitura das imagens, é possível compreender que aspectos da semiótica se fazem presentes na construção do conhecimento. Tais aspectos se encontram vívidos principalmente quando pretendemos abstrair algum tipo de conhecimento.

Quando falamos em conhecimento, podemos compreender vários aspectos, inclusive as questões relacionadas à matemática. Para obter conhecimento matemático, não basta apenas compreender seus conceitos, é necessário construir novas ideias por meio de diferentes procedimentos. A presente investigação buscou relacionar os conhecimentos matemáticos por meio de registros fotográficos, compreendendo que neste processo acontece uma intervenção semiótica; ou seja, o signo e seus significados são atuantes nos aspectos relacionados à representação de uma imagem. Por meio dos estudos aqui apresentados, foi possível identificar que uma abordagem semiótica apresenta um papel fundamental em relação à fotografia, pois 
é por meio dos signos que nos são apresentadas as informações e as características que uma imagem pode expressar.

Com o estudo da fotografia e sua representação semiótica segundo a concepção de Peirce, evidenciou-se que a fotografia, por apresentar uma representação semiótica, pode ser uma ferramenta para aprendizagens matemáticas, uma vez que, a partir de fotos, nesse caso, do cotidiano, é possível extrair elementos matemáticos do meio social, bem como, possibilitar a reflexão sobre o contexto social de diferentes perspectivas oportunizando a construção de conhecimentos que, às vezes, passam despercebidos na vida cotidiana, mas que ao serem analisados a partir de uma fotografia podem ser evidenciados e explorados sob um novo olhar.

Sendo assim, percebeu-se que a utilização da fotografia e sua representação semiótica no trabalho com aprendizagem matemática é um campo bastante promissor e que pode trazer resultados bastante positivos em relação ao pensamento de novos métodos para o ensino de conhecimentos matemáticos, uma vez que a matemática é vista com certo grau de dificuldade por muitos estudantes.

Trata-se, portanto, de desenvolver uma leitura do mundo a partir da interpretação semiótica dos registros fotográficos, para compreender como a matemática faz parte do nosso cotidiano e pode, portanto, ser mais bem entendida, posto que é instrumento de compreensão da vida e não uma ciência hermética, indecifrável.

\section{REFERÊNCIAS:}

ALMEIDA, Lourdes Maria Werle de; SILVA, Karina Alessandra Pessoa da. Abordagens Semióticas em Educação Matemática. Bolema, Rio Claro, V.32, n.61, p. 696-726, ago.2018. Disponível em: http://www.scielo.br/pdf/bolema/v32n61/0103-636Xbolema-32-61-0696.pdf. Acesso em: 20 nov. 2018.

AZEVEDO, Isabel; OLIVEIRA, Rosa Maria; LARDOSA, Fernando. Arte e Ciência, um novo olhar na Arte Contemporânea. In: MARTINS, Moisés de Lemos; PINTO, Manuel (Orgs.). Comunicação e Cidadania - Actas do $5^{\circ}$ Congresso da Associação Portuguesa de Ciências da Comunicação 2007, Braga: Centro de Estudos de Comunicação e Sociedade (Universidade do Minho), 2008, p. 1639-1649. Disponível em: http://www.lasics.uminho.pt/ojs/index.php/5sopcom/article/viewFile/150/146. Acesso em: 05 set. 2011.BARTHES, Roland. Le message photographique. Communications 1, p. 127-138, Paris: Seuil, 1961. Disponível em: https://www.persee.fr/docAsPDF/comm_0588-8018_1961_num_1_1_921.pdf. Acesso em: 13 nov. 2018.

BRUM, Alissom; SCHIMIDT, Sarai. Fotografando a matemática no Bairro: Estudo sobre Comunicação e Educação. Rio Grande do Sul: Feevale, 2015. 
FLORES, Onici. A leitura da charge. Canoas: Ulbra, 2002.

MACHADO, Arlindo. Máquina e imaginário: o desafio das poéticas tecnológicas. 3. ed. São Paulo: EDUSP, 2001.

MACHADO, Silvia Dias Alcântara (org.). Aprendizagem em matemática: registros de representação semiótica. 8. ed. Campinas, SP: Papirus, 2013.

MACIEL, Aníbal de Menezes; RÊGO, Rogéria Gaudêncio do; CARLOS, Erenildo João. Possibilidades Pedagógicas do Uso da Imagem Fotográfica no Livro Didático de Matemática. Bolema, v.31, no 57, p. 344-364. Rio Claro jan./abr. 2017. Disponível em: http://www.scielo.br/scielo.php?script=sci_arttext\&pid=S0103-

636X2017000100019\&lng=pt\&tlng=pt. Acesso em: 19 nov. 2018.

MARCONDES FILHO, Ciro. Dicionário da comunicação. São Paulo: Paulus, 2009.

MORITA, Gustavo. Ensaio fotográfico: o olhar em tempos de matemática. Educação, São Paulo, v. 239, p.1-1, 27 maio 2017. Disponível em:

<http://www.revistaeducacao.com.br/ensaio-fotografico-o-olhar-em-tempos-dematematica/>. Acesso em: 21 out. 2018.

NAGAMINI, Eliana. Questões teóricas e formação profissional em comunicação e educação. Ilhéus, BA: Éditus, 2016.

NIEMEYER, Lucy. Elementos de semiótica aplicados ao design. Rio de Janeiro: 2AB, 2003.

PAVANATI, Iandra. Tríptico: modelo de caracterização básica de imagens fixas para o processo didático-pedagógico de Ensino Médio. 2012, 206f. Tese (Doutorado em Engenharia e Gestão do Conhecimento) - Centro Tecnológico, Universidade Federal de Santa Catarina, Florianópolis, 2013.

RAMOS, Matheus Manzini. A fotografia e o tempo: possibilidades de pensar o tempo via fotográfico: Ponto e interstício. Jundiaí, SP: Paco Editorial, 2012.

SANTAELLA, Lucia. Matrizes da linguagem e pensamento: sonora visual verbal: aplicações na hipermídia. 3. ed. São Paulo: Iluminuras/FAPESP, 2005.

. O que é Semiótica. São Paulo: Brasiliense, 2006.

. O que é Semiótica. São Paulo: Brasiliense, 1983.

. Semiótica aplicada. São Paulo: Cengage Learning, 2008.

SANTAELLA, Lúcia; NÖTH, Winfried. Imagem: cognição, semiótica, mídia. 4. ed. São Paulo: Iluminuras, 2005.

SANTOS, Cleane Aparecida dos; NACARATO, Adair Mendes. Aprendizagem em Geometria na educação básica: a fotografia e a escrita na sala de aula. Belo Horizonte: Autêntica Editora, 2014.

SOUSA, Jorge Pedro. A tolerância dos fotojornalistas portugueses à alteração digital de fotografias jornalísticas. Revista Brasileira de Ciências da Computação, São Paulo, v. 22, p.75-94, dez. 1999. Disponível em: 
<http://www.portcom.intercom.org.br/revistas/index.php/revistaintercom/article/vie w/1001/904>. Acesso em: 09 abr. 2019.

SOUSA, Richard Perassi Luiz de. Roteiro didático da arte na produção do conhecimento. Campo Grande: Editora da UFMS, 2005.

Recebido em 13 de março de 2019

Aceito em 29 de abril de 2019

A e-Mosaicos Revista Multidisciplinar de Ensino, Pesquisa, Extensão e Cultura do Instituto de Aplicação Fernando Rodrigues da Silveira (CAp-UERJ) está licenciada com uma Licença Creative Commons - Atribuição-NãoComercial 4.0 Internacional.

Os direitos autorais de todos os trabalhos publicados na revista pertencem ao(s) seu(s) autor(es) e coautor(es), com o direito de primeira publicação cedido à e-Mosaicos.

Os artigos publicados são de acesso público, de uso gratuito, com atribuição de autoria obrigatória, para aplicações de finalidade educacional e não-comercial, de acordo com o modelo de licenciamento Creative Commons adotado pela revista. 